\title{
O ESPORTE NA ESCOLA A PARTIR DO CURRÍCULO DO ESTADO DE SÃO PAULO
}

\author{
Heitor Perrud Tardin ${ }^{1}$, Luiz Rogério Romero ${ }^{2}$ \\ ${ }^{1}$ Graduado em licenciatura em Educação Física na Universidade Estadual Paulista - UNESP, Campus de Presidente \\ Prudente, SP. ORCID iD: https://orcid.org/0000-0003-3349-4783. E-mail: heitor21perrud@gmail.com. \\ ${ }^{2}$ Doutor em Saúde Coletiva pela Universidade Estadual Paulista - UNESP, Campus de Botucatu, SP. Professor \\ Assistente Doutor junto ao Departamento de Educação Física da Universidade Estadual Paulista - UNESP, Campus de \\ Presidente Prudente, SP. Coordenador do Programa Residência Pedagógica Educação Física da UNESP, Presidente \\ Prudente, financiado pela Coordenação de Aperfeiçoamento de Pessoal de Nível Superior - CAPES. ORCID iD: \\ https://orcid.org/0000-0002-7456-0946. E-mail: luiz.romero@unesp.br.
}

\section{RESUMO}

A década de 1980 representou um importante período para ensinar e aprender a Educação Física nas escolas, sobretudo, considerando aspectos metodológicos e conteúdos abordados. Pode-se reconhecer que as mudanças de metodologias instrumentalizaram a prática do movimento, no entanto, sem ressaltar aspectos de cunho pedagógico ou crítico. Neste cenário, o esporte se caracteriza como prática sociocultural e, no ambiente escolar, se deve questionar a forma de ensino distanciando-se da reprodução de estereótipos do alto rendimento e da formação alienada. Desse modo, torna-se relevante analisar a abordagem do esporte no contexto educacional regular. Tem-se como objetivo, analisar a inserção do esporte na Educação Física Escolar para o Ensino Fundamental e Médio a partir da Proposta Curricular do Estado de São Paulo. Trata-se de estudo documental quantitativo e qualitativo. Utilizou-se também levantamento da proporcionalidade da distribuição de temas relacionados ao esporte e outros enfoques de conteúdo. Inicialmente foi organizada a leitura sistematizada do texto da Proposta Curricular do Estado de São Paulo. Foram identificados 68 temas definidos para abordagem desde o EF até o EM, a partir dos Cadernos do Professor. Observou-se esportes, danças, ginásticas, capacidades físicas, corpo, saúde, beleza entre outros. Destacaram-se trinta temas e conteúdos diretamente relacionados ao esporte, representando $44 \%$ do total. 0 esporte é conteúdo predominante, apesar dos reconhecidos avanços em relação aos momentos anteriores, identificaram-se lacunas para subsidiar o desenvolvimento global do aluno. Sugere-se a proposição de estudos que auxiliem nas ações educacionais do docente da área e avançar no sentido de inovação de ensino esportivo na escola.

Palavras-chave: Currículo. Educação Física Escolar. Metodologia de Ensino. Esporte escolar.

\section{SPORT IN SCHOOL FROM THE CURRICULUM OF THE STATE OF SÃO PAULO}

\section{ABSTRACT}

The 1980s represented an important period for teaching and learning Physical Education in schools, especially considering methodological aspects and content covered. It can be recognized that changes in methodologies have instrumentalized the movement's practice, however, without highlighting aspects of a pedagogical or critical nature. In this scenario, sport is characterized as a socio-cultural practice and, in the school environment, the form of teaching must be questioned, distancing itself from the reproduction of stereotypes of high performance and alienated training. Thus, it becomes relevant to analyze the approach to sport in the regular educational context. The objective is to analyze the insertion of sport in Physical Education at School for Elementary and High School from the Curricular Proposal of the State of São Paulo. This is a quantitative and qualitative documentary study. A survey of the proportionality of the distribution of topics related to sport and other content approaches was also used. Initially, the systematic reading of the text of the Curricular Proposal of the State of São Paulo was organized. 68 themes were identified to be addressed from the EF to the EM, from the Teacher's Notebooks. Sports, dances, gymnastics, physical abilities were observed; body, health, beauty among others. Thirty themes and content directly related to sport stood out, representing $44 \%$ of the total. Sport is predominant content, despite the recognized advances in relation to previous moments, gaps were identified to subsidize the student's global 
development. It is suggested to propose studies that assist in the educational actions of the teacher in the area and move towards innovation in sports education at school.

Keywords: Curriculum. Physical School Education. Teaching methodology.

\section{DEPORTE EN LA ESCUELA DE LA PROPUESTA DE CURRICULUM DEL ESTADO DE SÃO PAULO}

\section{RESUMEN}

La década de los 80 representó un período importante para la enseñanza y el aprendizaje de la Educación Física en las escuelas, especialmente considerando los aspectos metodológicos y los contenidos cubiertos. Se puede reconocer que los cambios en las metodologías han instrumentalizado la práctica del movimiento, sin embargo, sin resaltar aspectos de carácter pedagógico o crítico. En este escenario, el deporte se caracteriza como una práctica sociocultural y, en el ámbito escolar, se debe cuestionar la forma de enseñar, distanciándose de la reproducción de estereotipos de alto rendimiento y entrenamiento alienado. Por tanto, cobra relevancia analizar el enfoque del deporte en el contexto educativo habitual. El objetivo es analizar la inserción del deporte en la Educación Física en la Escuela de Bachillerato y Bachillerato a partir de la Propuesta Curricular del Estado de São Paulo. Se trata de un estudio documental cuantitativo y cualitativo. También se utilizó una encuesta sobre la proporcionalidad de la distribución de temas relacionados con el deporte y otros enfoques de contenido. Inicialmente se organizó la lectura sistemática del texto de la Propuesta Curricular del Estado de São Paulo. Se identificaron 68 temas para ser abordados desde el EF al EM, desde los Cuadernos del Profesor. Se observaron deportes, bailes, gimnasia, habilidades físicas; cuerpo, salud, belleza entre otros. Se destacaron treinta temas y contenidos directamente relacionados con el deporte, que representan el $44 \%$ del total. El deporte es contenido predominante, a pesar de los reconocidos avances en relación a momentos anteriores, se identificaron brechas para subsidiar el desarrollo global del estudiante. Se sugiere proponer estudios que coadyuven en la acción educativa del docente en el área y avancen hacia la innovación en la educación deportiva en la escuela.

Palabras clave: Currículum. Educación Física Escolar. Metodología de la enseñanza.

\section{INTRODUÇÃO}

Este estudo foi realizado durante as atividades decorrentes do processo de formação de professores, vinculado ao Programa Residência Pedagógica (PRP) em Educação Física. Trata-se de uma iniciativa da Coordenação de Aperfeiçoamento de Pessoal de Nível Superior (CAPES) com o objetivo de implementar ações inovadoras articuladas entre teoria e prática nos cursos de licenciatura, em parceria com as redes públicas de educação básica (BRASIL, 2018).

Neste sentido, considera-se importante retomar os seguintes apontamentos sobre a construção da Educação Física Escolar. Segundo Neira (2016), a Educação Física passou por várias mudanças em seus sentidos e objetivos, se adequando às demandas sociais. Portanto, a década de 1980 representou um importante período referente ao modo de ensinar e aprender a Educação Física nas escolas, sobretudo, considerando aspectos metodológicos e conteúdos abordados.

Para Betti et al. (2015):

Com o retorno do Brasil à democracia no início dos anos 1980, as liberdades civis emergentes promoveram novas ideias para alcançar a justiça social. Também levaram a um renascimento do interesse por propostas críticas no setor acadêmico, com implicações significativas para a educação escolar. Esse processo de democratização favoreceu a criação de propostas para a renovação do PE no país (BETTI et al., 2015, p. 5).

Neste trecho, Betti et al. (2015) apresenta que com a mudança política novas ideias sobre justiça social foram promovidas para a sociedade, e este processo influenciou a renovação da Educação Física, partindo para uma visão mais crítica. 
Porém, Bracht (1992) afirma que a mudança de metodologia instrumentalizou a prática do movimento, no entanto, sem ressaltar aspectos de cunho pedagógico ou crítico. Para Soares et al (1992), tem-se a necessidade de transcender está temática:

[...] Educação Física, tomando-a como matéria escolar que trata, pedagogicamente, temas da cultura corporal, ou seja, os jogos, a ginástica, as lutas, as acrobacias, a mímica, o esporte e outros. Este é o conhecimento que constitui o conteúdo da Educação Física (SOARES et al., 1992, p. 10).

Bracht (1992) aponta que em determinados momentos, a Educação Física assume o papel de base para o esporte de rendimento, colocando o contexto escolar como mero meio de reprodução de seus códigos e representações. Apesar das mudanças citadas, anteriormente, certos aspectos de uma Educação Física com enfoque no desporto ainda podem ser encontrados até os dias de hoje.

Para Soares et al. (1992), o esporte se caracteriza como prática sociocultural $e$, no ambiente escolar, se deve questionar a forma de ensino distanciando-se da reprodução de estereótipos do alto rendimento e da formação alienada. Apontam ainda que o esporte, como conteúdo da Educação Física escolar, deve proporcionar aos alunos entendimentos sobre regras e valores da sociedade atual.

Soma-se ainda, pressupostos relacionados ao processo de reflexão-ação (MEDINA, 1992) e autorreflexão (SANTIN, 2007), no sentido de ampliar o desenvolvimento geral do indivíduo, principalmente com o uso de questionamentos e problematização.

Para Sedorko e Finck (2016), o esporte é um dos maiores fenômenos socioculturais da atualidade e representa inúmeros sentidos e significados. Este fato reforça a necessidade de uma contextualização reflexiva e crítica sobre o esporte e as diferentes realidades socioculturais.

Esta ideia ainda é reforçada por Bracht (2014), sendo que o autor afirma que é necessária uma compreensão do movimento além das reações biológicas. Trata-se de uma complexidade que é diferente em cada sujeito e envolve estruturas e contextos histórico-sociais.

$\mathrm{Na}$ abordagem crítico-emancipatória utilizada por Kunz (2014) alunos e professor devem fazer uma análise sobre o esporte para desenvolver a capacidade de aprofundamento além do movimento. Ressalta ainda a importância do pensamento crítico durante as aulas. Compreende-se, portanto, que a função do professor de Educação Física vai além de ensinar o movimento. A contribuição deve ser muito mais ampla, ou seja, o professor deve favorecer a formação integral do aluno.

Desse modo, Betti et al. (2015) afirmam que a Educação Física escolar passou por uma série de reformulações, conferindo-lhe um caráter mais crítico e humanista e se distanciando do caráter unicamente esportivo.

Para Betti et al. (2015) as aulas de Educação Física com objetivos de formação crítica, devem propiciar aos alunos um ambiente em que possam ter vivências e principalmente se expressar. A Educação Física deve ser compreendida como uma área híbrida, em que a educação promove saúde e a saúde promove educação (BETTI; GOMES-DA-SILVA, 2019). No entanto, muitas lacunas ainda permaneceram em aberto. Exemplo disso são evidenciados estudos que ainda situam o esporte como único conteúdo (CESANA; TOJAL; DRIGO, 2018).

Segundo Betti e Gomes-da-Silva (2019), para ocorrer mudanças no currículo e nos objetivos da Educação Física, são necessários esforços que vão além de alterações na matriz escolar. Estas ações envolvem revisões desde a formação inicial docente até a reestruturação do Projeto Político Pedagógico da escola.

Atualmente, tem-se observado mudanças em relação à organização da Educação Física Escolar e a inserção de outros conteúdos além de práticas desportivas. Em relação ao Cenário paulista, as danças, lutas, ginásticas discussões sobre saúde, consciência corporal entre outros eixos são identificados no Currículo do Estado de São Paulo (SÃO PAULO, 2014).

Este documento ordena os conteúdos, as competências e as habilidades da disciplina de acordo com a série/ano escolar. Desse modo, torna-se relevante analisar a abordagem do esporte no contexto educacional regular. O presente estudo tem como objetivo analisar a inserção do esporte na Educação Física Escolar para o Ensino Fundamental e Médio a partir do Currículo do Estado de São Paulo. 


\section{DELINEAMENTO METODOLÓGICO}

Trata-se de estudo documental com características quantitativas e qualitativas. Pesquisas documentais caracterizam-se pela identificação, verificação e apreciação de documentos com uma finalidade específica (THOMAS; NELSON, 2012). Nesta perspectiva de investigação, busca-se o aprofundamento e análise de materiais bibliográficos, documentos e outros registros para a produção de novos conhecimentos. Utilizou- se também levantamento da proporcionalidade da distribuição de temas relacionados ao esporte e outros enfoques de conteúdo.

Inicialmente foi organizada a leitura sistematizada do texto do Caderno do Professor do Estado de São Paulo, especificamente na área de Educação Física. A primeira fase obedeceu à leitura corrente de todo o texto e o destacamento do tema esporte entre os conteúdos.

A segunda fase foi realizada com o recurso de busca por palavras-chave do programa computadorizado Adobe Acrobat Reader DC, os termos buscados neste momento foram: futebol; futsal; volei; voleibol; basquete; basquetebol; handebol; handball. Este procedimento teve a função de identificar os tópicos destinados ao tema esporte e sua respectiva descrição de conteúdo, além disso, revelou o número de vezes que estes esportes são citadas nos Cadernos do Professor. levantamento e identificação de temas/conteúdos, foi organizado um quadro descritivo segundo a seriação de ensino e bimestre letivo. Estes procedimentos auxiliaram a identificação dos tópicos relacionados ao esporte.

\section{RESULTADOS E DISCUSSÃO}

Apresenta-se a seguir os dados evidenciados a partir dos processos de identificação das ações destinadas ao esporte, segundo o Currículo de Estado de São Paulo (SÃO PAULO, 2014).

Foram identificados 68 temas definidos para abordagem em Educação Física Escolar entre o 60 ano do Ensino Fundamental e o 3ㅇan ano do Ensino Médio, a partir dos Cadernos do Professor da Proposta Curricular do Estado de São Paulo. Dentre os tópicos de estudo, observou-se esportes, danças, ginásticas, capacidades físicas, corpo, saúde, beleza entre outros.

Dentre estes, destacaram-se trinta temas e conteúdos diretamente relacionados ao esporte, representando $44 \%$ do total (Gráfico 1).

Após este procedimento de

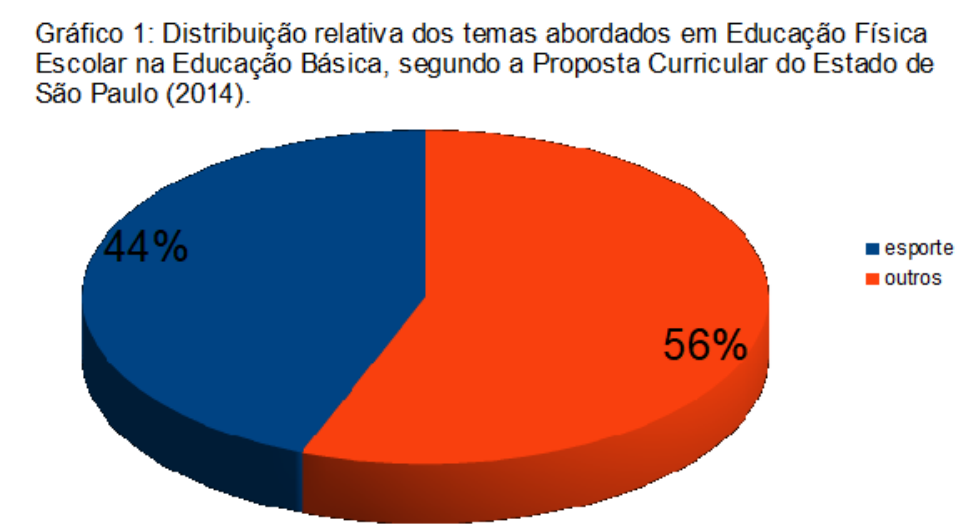

Fonte: Os autores. 
O Gráfico 1 apresenta que as temáticas relacionadas ao esporte representam $44 \%$ do conteúdo da Educação Física escolar, considerando o período entre o sexto ano do Ensino Fundamental e o terceiro ano do Ensino Médio. Destaca-se que o esporte aparece de forma majoritária no cenário escolar. Esta perspectiva de proporção reforça a necessidade de abordar o tema esporte para além do aprendizado de gestos atléticos, da sistematização de movimentos e do desempenho técnico.

Betti (2005) destaca a cultura corporal de movimento e toda a simbologia que representa em sociedade, a partir da problematização e crítica ao "fazer por fazer". Isso não significa que a Educação Física não deva proporcionar aos alunos situações de vivências motoras, todavia há que se garantir o desenvolvimento de senso crítico dos estudantes nas aulas ligadas ao referido componente curricular.

Souza e Paixão (2015) ao investigar a prática pedagógica do professor de Educação Física, na perspectiva dos alunos de Ensino Médio, descrevem a resistência de professores na aplicação de referenciais teórico-metodológicas e estratégias oferecidas no curso de formação inicial. Em contrapartida, suas práticas se aproximam das aulas vivenciadas enquanto alunos da educação básica. Este é um dos aspectos que concercem à predominância do conteúdo esporte.

Neste panorama, Betti (1999) ressalta que o professor deve propiciar aos alunos o entendimento dos mais variados sentidos do esporte, como resolução de conflitos, compreensão do esporte, alterações de regras e principalmente devem-se incentivar debates sobre questões sociais.
Neste sentido, Betti e Gomes-da-Silva (2019) defendem a aula de Educação Física como espaço privilegiado para a comunicação e linguagem. Apontam que jogos e outros conteúdos formam a base para relações sociais e intrapessoais, favorecendo o desenvolvimento dos aspectos motores, sociais e cognitivos.

Estes apontamentos reforçam a necessidade de reavaliação do processo de formação de professores, sobretudo, a integralidade entre teoria e prática no efetivo exercício profissional e contextualização do esporte em panorama ampliado. Tardif; Lessard (2005) ressaltam que o professor não se desenvolve apenas no processo de formação inicial, mas é durante ele, sendo que paradigmas se quebram e novas perspectivas se formam.

As atividades identificadas apresentam limitações, pois abordam pouco sobre a modalidade desportiva e demonstram ênfase nas respectivas técnicas e táticas básicas.

Segundo Neira (2015) "o caráter exaustivo das descrições que compõem os cadernos do professor e do aluno permite atribuir ao material uma conotação prescritiva, principalmente porque o material do aluno contém exercícios correspondentes às situações de aprendizagem previstas no caderno do professor".

A Figura 1, retirada do Caderno do Professor de Educação Física, do ano de 2014, explicita como cada conteúdo deve ser trabalhado de acordo com cada série/ano no referido componente curricular.

Por vez, na Figura 2, estão representados os temas e conteúdos a serem trabalhados a partir do $6^{\circ}$ ano do Ensino Fundamental até o $9^{\circ}$ ano. 


\section{Quadro de conteúdos do ensino védio}

\begin{tabular}{|c|c|c|}
\hline 14série & 2 série & "wsérie \\
\hline 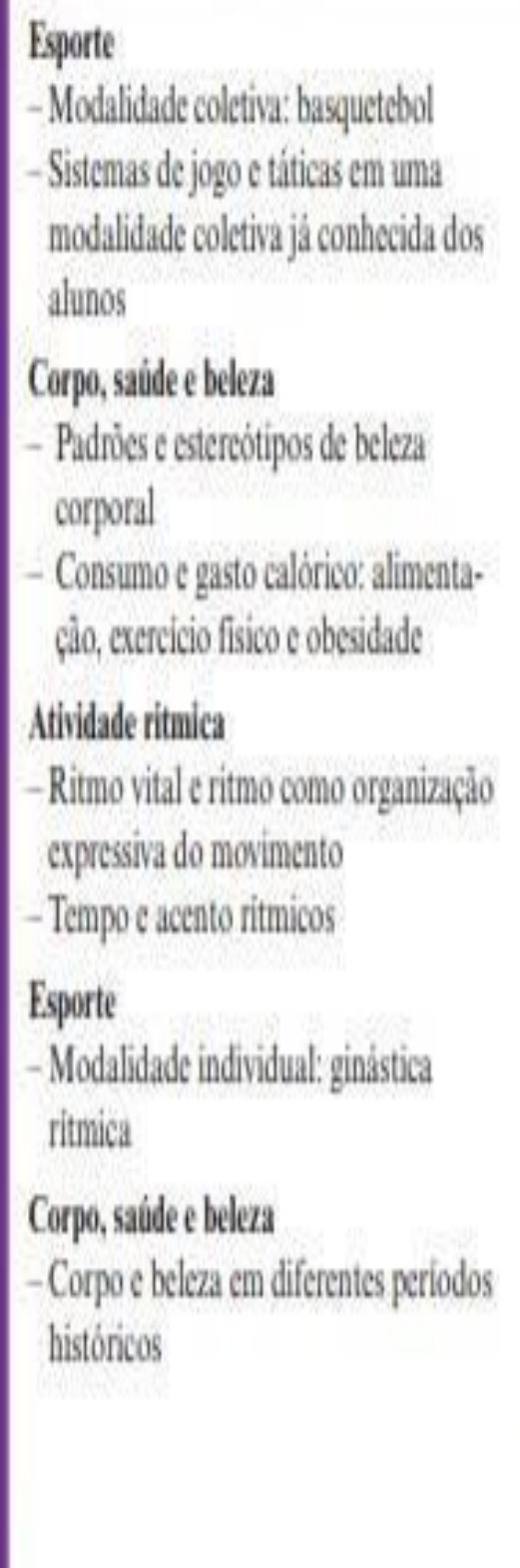 & 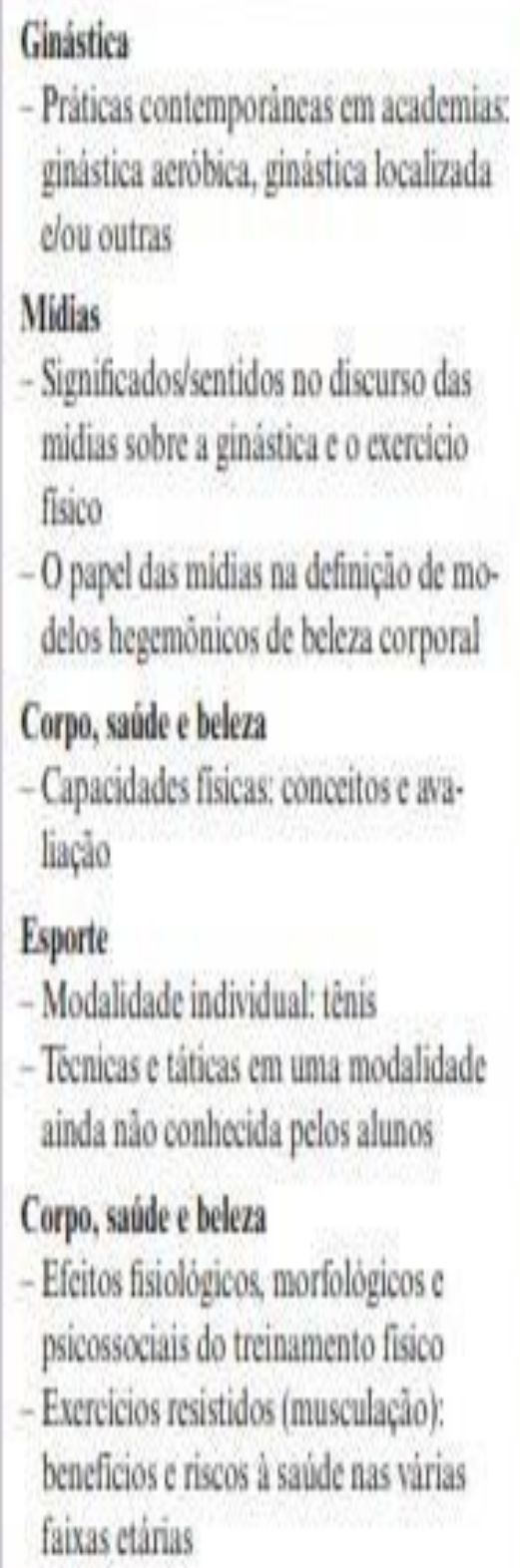 & 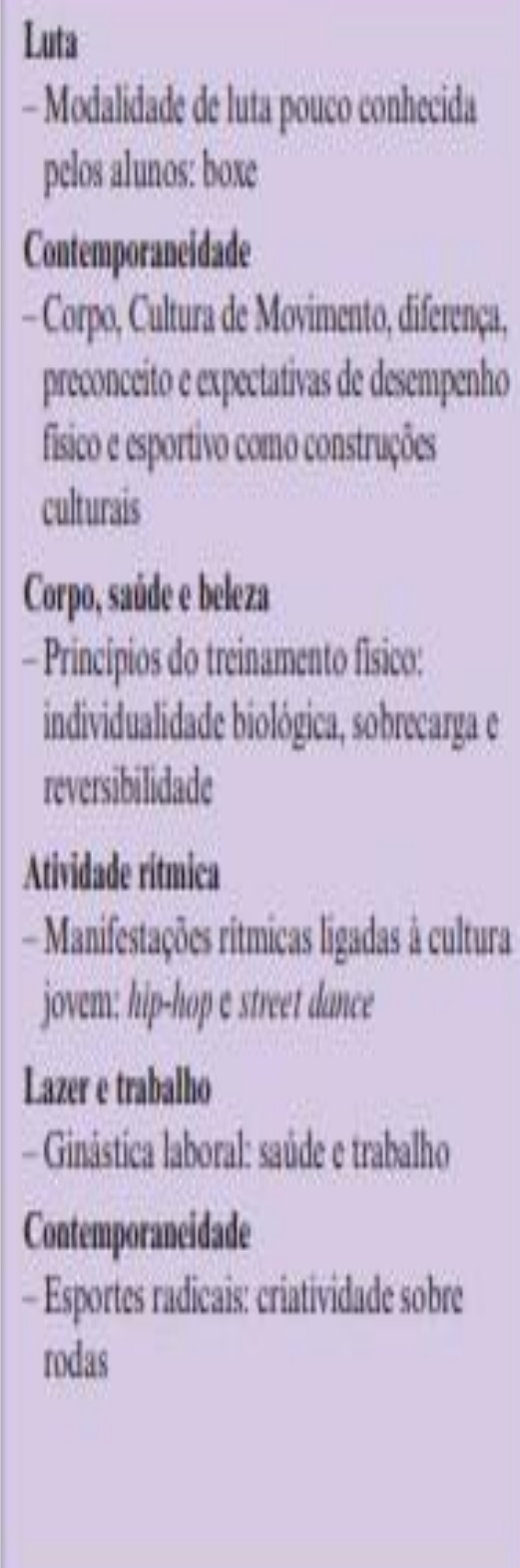 \\
\hline
\end{tabular}

Fonte: Caderno do Professor 2014 (SÃO PAULO, 2014). 
Figura 2 - Quadro de Conteúdos do Ensino Fundamental - Anos Finais

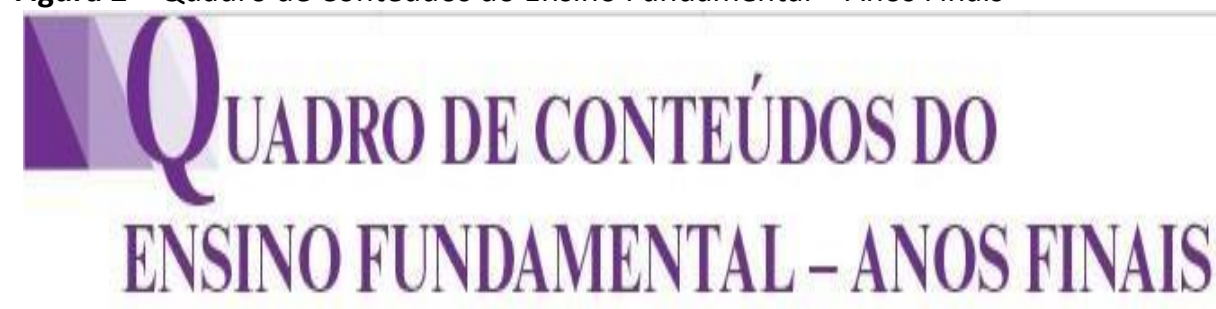

\begin{tabular}{|c|c|c|c|}
\hline $5^{2}-\operatorname{sé}^{2} i \mathrm{c} / 0^{0}$ ano & (a) série/7? ano & $7^{9}$ série $188^{\circ}$ ano & $8^{2}$ série 99 ano \\
\hline 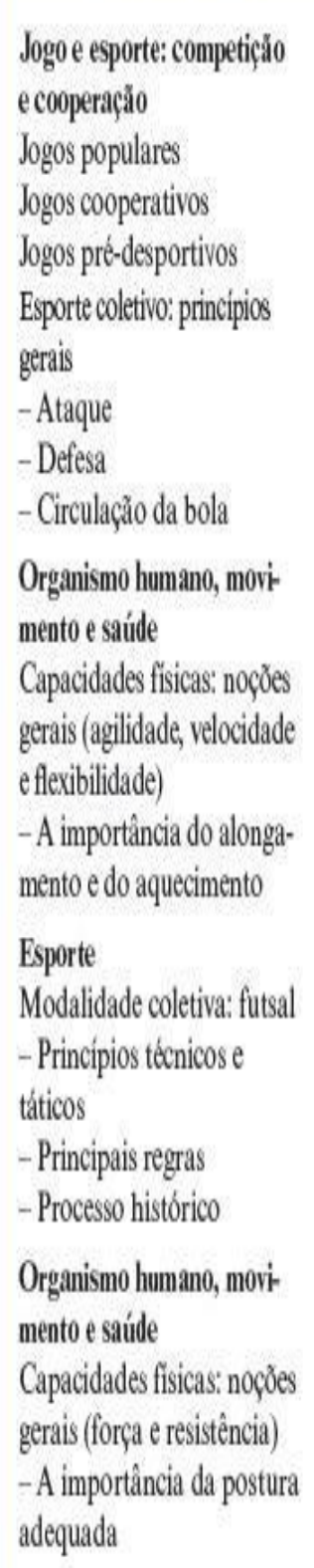 & 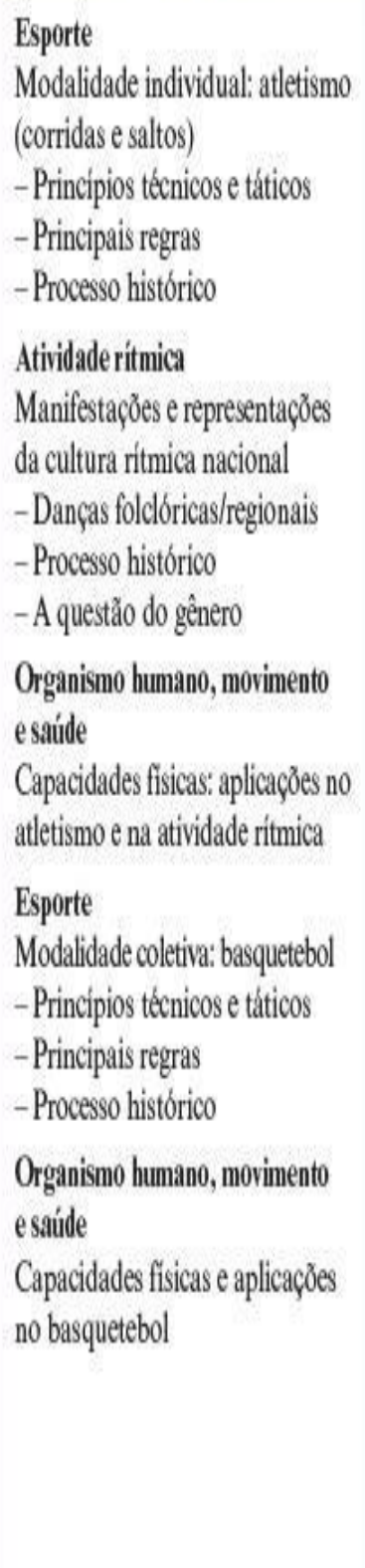 & $\begin{array}{l}\text { Esporte } \\
\text { Modalidade individual: atletismo } \\
\text { (corridas, arremessose lançamen- } \\
\text { tos) } \\
\text { - Princíipios técnicos e táticos } \\
\text { - Principais regras } \\
\text { - Processo histórico } \\
\text { Luta } \\
\text { Modalidade: caratê. } \\
\text { - Princípios técnicos e táticos } \\
\text { - Principais regras } \\
\text { - Processo histórico } \\
\text { Organismo humano, movimento } \\
\text { e saíde } \\
\text { Capacidades fisicas: aplicaçoes no } \\
\text { atletismo e na luta } \\
\text { Esporte } \\
\text { Modalidade coletiva: a escollher } \\
\text { - Técnicas e táticas como fatores } \\
\text { de aumento da complexidade do } \\
\text { jogo } \\
\text { - Noçoes de arbitragem } \\
\text { Ginástica } \\
\text { Práticas contemporâneas } \\
\text { - Princípios orientadores } \\
\text { - Técnicas e exercicios }\end{array}$ & $\begin{array}{l}\text { Luta } \\
\text { Modalidade: capoeira } \\
\text { - Capoeira como luta, jogo e } \\
\text { esporte } \\
\text { - Principios técnicos e táticos } \\
\text { - Processo histórico } \\
\text { Atividade rítmica } \\
\text { Manifestaçoes ritmicas ligadas } \\
\text { à cultura jovem: hip-hope } \\
\text { street dance } \\
\text { - Coreografias } \\
\text { - Diferentes estilos como } \\
\text { expressåo sociocultural } \\
\text { - Principais passose } \\
\text { movimentos } \\
\text { Esporte } \\
\text { Modalidade coletiva: futebol } \\
\text { de campo } \\
\text { - Técnicas e táticas como fato- } \\
\text { res de aumento da complexida- } \\
\text { de do jogo } \\
\text { - Noçoes de arbitragem } \\
\text { - Processo histórico } \\
\text { - } 0 \text { esporte na comunidade } \\
\text { escolar e em seu entorno: espa- } \\
\text { cos, tempos e interesses } \\
\text { - Espetacularização do esporte } \\
\text { e o esporte profissional } \\
\text { - 0 esporte na mídia } \\
\text { - Os grandes eventos esportivos }\end{array}$ \\
\hline
\end{tabular}

Fonte: Caderno do Professor 2014 (SÃO PAULO, 2014). 
Como identificados nas Figuras 1 e 2, as recomendações do Currículo para o ensino de esportes possuem limitações, expressando ênfase em assuntos técnicos e táticos, e secundariza a construção de possibilidades pedagógicas existentes no desporto. Para Neira (2016, p. 247):

A concepção que inspira o documento se afasta dos debates contemporâneos da Educação Física. Não há menção às questões que afligem a sociedade atual e à característica multicultural da população escolar. Também surpreende a concepção instrumental que norteia $o$ caderno do professor, que contém textos superficiais, tendenciosos e atividades fechadas, com pouca possibilidade de modificação pelos professores.
Segundo Betti e Gomes-da-Silva (2019, p. 117):

Assim reconhecemos que a aula é de responsabilidade do professor, com sua formação política e profissional; do aprendente, com seus interesses sociais $\mathrm{e}$ motivações delineados em um contexto cultural; e do ambiente construído para a aprendizagem, que inclui desde a estrutura física espacial, arquitetônica e material didático disponível, até a lógica de organização funcionamento escolar implementados pelas gestões e políticas públicas.

Figura 3 - Implicações na aula de Educação Física

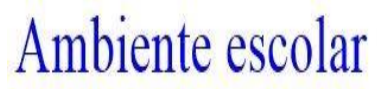

\section{Politicas Públicas}
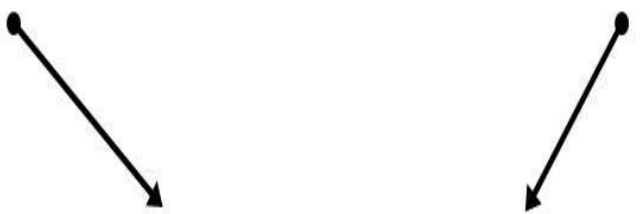

\section{Aula de Educação}
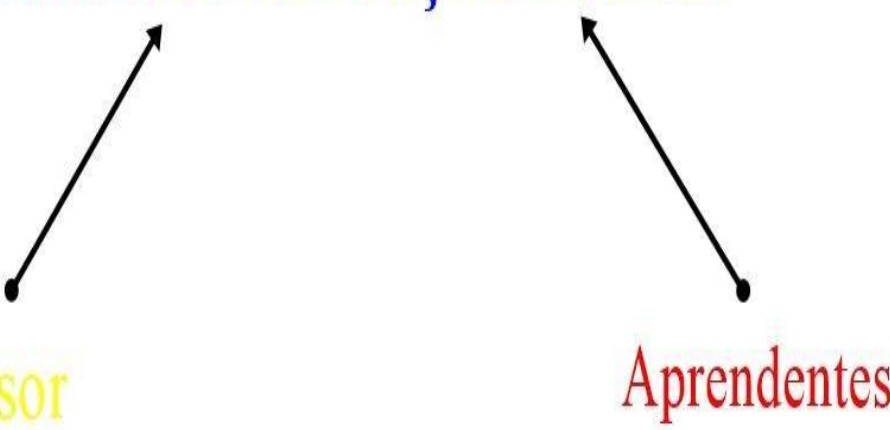

Fonte: Os autores.

Neste sentido, os autores indicam que o professor tem papel central no processo de ensino aprendizagem. No entanto, consideram fundamentais, não é o único fator, a estrutura da escola, a organização dos conteúdos (que são preestabelecidos pelo Currículo) e os alunos fazem parte deste cenário e são de extrema importância.

Para Betti et al. (2015), apesar deste novo currículo efetuar a tentativa de implantar a 
Cultura de Movimento, observa-se que a Educação Física ainda possui intenso vínculo com a reprodução esportiva na escola. Considera-se, portanto, a existência de uma lacuna que dificulta a priorização da formação global do aluno e da construção de consciência crítica e contextual. Neira (2016, p. 246) descreve este panorama:

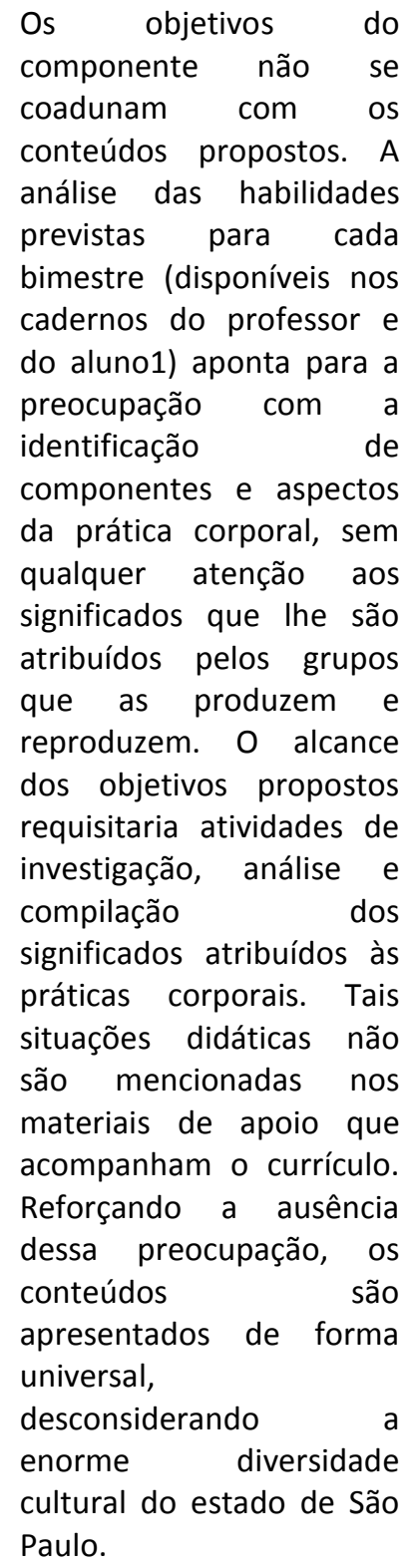

Lopes, Tavares e Santos (2017) reforçam a ideia de que existem lacunas na Proposta:

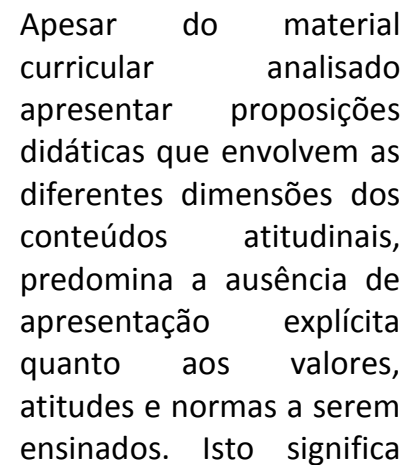

dizer que os debates e discussões sobre os conteúdos podem ou não promover um ambiente pedagógico para o ensino da tolerância, respeito às minorias, solidariedade, etc. Esta falta de clareza acerca dos valores orientadores para as ações/decisões educativos propostas nas unidades didáticas pode permitir que as práticas pedagógicas tornem-se contraditórias aos propósitos educacionais da escola e inclusive da concepção do próprio material curricular quanto à formação crítica e orientada para a cidadania (LOPES; TAVARES; SANTOS, 2017, p. 823).

Milani e Darido (2016) afirmam que, apesar de o próprio Caderno do Professor indicar uma metodologia menos tecnicista e mais focada na formação atitudinal do aluno, o mesmo ainda enfatiza as dimensões procedimentais e conceituais.

Saviani (1997) aponta para a importância do desenvolvimento crítico do aluno em busca da autonomia. Kunz (2012) defende a formação crítica dos alunos utilizando o esporte como base para a contextualização. Betti e Gomes-da-Silva (2019) ressaltam que um dos focos das aulas de Educação Física é ensinar ao aprendentes viver de modo autônomo, crítico e criativo. Milani e Darido (2016) indicam que a escola contribui diretamente para a formação de um sujeito que viverá em sociedade multicultural, onde o indivíduo deve ser autônomo e crítico em relação a sua moral e ética.

Além dos esportes propriamente ditos, as aulas de Educação Física devem ainda conter jogos que, abordem os aspectos do desporto e sejam inclusivos, propiciando vivências esportivas para todos e não apenas aos mais desenvolvidos em aspectos motores. Betti e Gomes-da-Silva $(2019$, ) acrescentam que: “[...] uma pequena variação em um jogo, sugerindo problematizações, ou novos desafios, alterando regras, ou espaço e número de jogadores, entre outras possibilidades, já pode torná-lo favorável a novas aprendizagens no contexto singular de 
cada turma de aprendentes".

Outro fato constatado na Proposta Curricular (SÃO PAULO, 2014) refere-se à manutenção de esportes tradicionais, como futebol, basquete e voleibol, fazendo uma busca no localizador de palavras do Adobe Acrobat pelos termos futebol; futsal; vôlei; voleibol; basquete; basquetebol; handebol, encontra-se 595 menções a essas expressões.

Neste cenário, tende a diminuir o espaço para os esportes não convencionais como, por exemplo: hóquei (e suas variações), atividades aquáticas, Sepaktakraw, golfe, lacrosse, futebol americano, basquete $3 \times 3$, curling, malha, iatismo, tiro com arco, hipismo, esportes de inverno, por exemplo, não possuem espaço garantido nos quatro anos de Ensino Fundamental - anos finais e Ensino Médio. Apesar de estes exemplos estarem longe de serem presentes na cultura brasileira, sua inserção na Educação Física pode ser interessante para aumentar e variar as possibilidades dentro da aula, visto que muito pode ser discutido por meio de culturas diferentes e distantes. Limitar o número de vivências que a serem desenvolvidas no âmbito escolar pode acarretar em prejuízos motores, críticos e culturais para todos os alunos.

Em contrapartida, outras dificuldades recorrentes se apresentam para o efetivo exercício da docência, como o limitado número de aulas de Educação Física, infraestrutura e materiais dentre outros fatores (CANESTRARO; ZULAI; KOGUT, 2008). Este fato ainda é confirmado por Rufino, Benites e Souza Neto (2017) que apontam, entre outros motivos, a falta de materiais (didáticos e de infraestrutura), ligado a isso, condições de trabalho precárias, com turmas superlotadas, carga horária elevada e baixa remuneração, entre outros empecilhos, dificultam o trabalho docente interferindo diretamente nas possibilidades de trabalhar outros conteúdos além do já conhecido e tradicional.

Para comparação, tomam-se como base os Jogos Olímpicos de Verão. Segundo o site oficial das olimpíadas de verão de Tóquio 2020 (INTERNATIONAL OLYMPIC COMMITTEE, 2020), o evento contará com 33 esportes diferentes. Apesar de ser um Mega Evento visando apenas o alto desempenho, esse espaço entre o número de esportes praticados nas Olimpíadas e a quantidade levada aos alunos, ilustra a diferença de vivências que o esporte possibilita e a quantidade oferecida na realidade.
Segundo Barros e dos Reis (2013, p. 1):

Conclui-se que os jogos

não convencionais contribuem

expressivamente na

formação da criança, tanto

em relação a sua autonomia corporal (quando joga) quanto a sua autoria (quando modifica e sugere jogos). Essa contribuição para formação da criança vai muito além, influenciando na sua formação pessoal, influenciando tanto sua formação físico- biológica que era objetivo dos higienistas, quanto na formação psicossocial, contribuindo para tomada de decisões e formação de caráter, atual objetivo da educação física.

Além disso, contribui para a valorização e legitimação da Educação Física enquanto componente curricular vinculado ao projeto político pedagógico da escola.

Todavia, devem-se destacar os avanços propiciados pela presente organização curricular. A Proposta possibilita ajustes e alterações para o atendimento da realidade de cada contexto escolar.

Enfim, o Caderno do Professor, criado pelo programa São Paulo Faz Escola, apresenta orientações didáticopedagógicas e traz como base o conteúdo do Currículo Oficial do Estado de São Paulo, que pode ser utilizado como complemento à Matriz Curricular. Observem que as atividades ora propostas podem ser complementadas por outras que julgarem pertinentes ou necessárias, dependendo do seu planejamento e da adequação da proposta de ensino deste material à 
realidade da sua escola e de seus alunos. O Caderno tem a proposição de apoiá-los no planejamento de suas aulas para que explorem em seus alunos as competências e habilidades necessárias que comportam a construção do saber e a apropriação dos conteúdos das disciplinas, além de permitir uma avaliação constante, por parte dos docentes, das práticas metodológicas em sala de aula, objetivando a diversificação do ensino e a melhoria da qualidade do fazer pedagógico (SÃO PAULO, 2014, p. 4).

Betti e Gomes-da-Silva (2019) defendem que o professor é figura central e ativa no processo de ensino e de aprendizagem, e não submisso a determinismos e ideologias estabelecidas. Desse modo, entende-se ainda a necessidade de esforços de diversos atores para avanços na abordagem do esporte nas aulas de Educação Física Escolar, perpassando pela formação inicial do professor e atuação inovadora, promovendo novas vivências, novos desafios e usando o conteúdo não apenas como movimento, mas sim como um meio de formar cidadãos mais críticos e autônomos e para isso, necessita-se de condições adequadas de infraestrutura e trabalho e sistematização curricular. Neste sentido, Araújo e Neira (2014, p. 2) afirmam que:

A dificuldade em avaliar os efeitos da prática do currículo proporciona as condições de perpetuação do problema. A falta de atenção com relação aos privilégios concedidos a determinadas manifestações corporais sem critérios explícitos, a maneira como elas são apresentadas aos alunos ou a desconsideração do patrimônio cultural corporal da comunidade pode fazer com que a ação curricular se afaste dos objetivos de uma escola compromissada com a formação de cidadãos que circularão na esfera pública.

Salienta-se, portanto, que o esporte se configura como importante temática para a Educação Física Escolar, além de instrumento para a abordagem de conteúdos que transcendam o panorama técnico e que potencialize a formação de cidadãos críticos e participativos nas possibilidades da Cultura Corporal de Movimento e comprometidos com suas responsabilidades em sociedade.

No entanto, existem inúmeras dificuldades que se interpõem entre o idealizado pela literatura e o real contexto escolar. Essas realidades vividas nas escolas não podem ser generalizadas, pois, cada instituição apresenta características únicas. Segundo o Censo Escolar São Paulo (2014) são mais de 5.800 escolas no Estado de São Paulo. Portanto, uma Proposta Curricular deve possibilitar ações educativas contextualizadas de acordo com potencialidades e necessidades locais.

\section{CONCLUSÕES}

O esporte é conteúdo predominante na Educação Física escolar no Currículo do Estado de São Paulo. Apesar dos reconhecidos avanços em relação aos momentos anteriores da história, identificou-se ainda a apresenta de lacunas em relação aos subsídios para o desenvolvimento global do aluno. Esse hiato apresentado pelo Currículo envolve a valorização de uma gama limitada de vivências, sendo que a abordagem incentivada pelo documento em questão, restringe os conteúdos em apenas aspectos técnicos e táticos, vislumbrando um retrocesso em questões metodológicas, principalmente valorizando o movimento por movimento e o esporte de rendimento.

Segundo a literatura evidenciada neste presente trabalho, o esporte pode contribuir de modo relevante para fins pedagógicos, desde que seja planejado e executado de forma a considerar outros aspectos além da motricidade. Portanto, a formação inicial de professores deve ser organizada no sentido de ampliar as ações a partir do esporte na escola. Também, orientar professores em atuação na Educação Básica e futuros docentes na prospecção de experiências diárias para a ressignificação e aperfeiçoamento de sua prática. Nesta perspectiva, o Caderno do 
Professor deve amparar as aulas e oferecer possibilidades de pedagógicas a partir dos conteúdos envolvendo o esporte.

Contudo, sugere-se uma reflexão individual ao professor a respeito de como o esporte é abordado em suas aulas e o que poderia ser feito para abranger mais aspectos além da motricidade. Sugere-se aqui, como meio para auto reflexão, a análise de plano de aula segundo Smyth (1992) o autor elenca quatro etapas onde o professor estuda sua aula desde antes de sua formação inicial até os próprios atos durante a aula. Ainda sobre esse trabalho de reflexão sobre a prática do professor, pode-se apresentar o trabalho de Ortiz (2003), por meio do qual a autora defende a reflexão sobre a ação como meio de aumentar a qualidade da aula de cada professor.

As dificuldades enfrentadas pela Educação Física são multifatoriais, o que deixa ainda mais complexa a busca por soluções. Além disso, mais estudos são necessários para um aprofundamento teórico sobre a abordagem do esporte no Currículo do Estado de São Paulo, pois como já citado anteriormente, a Educação Física representa uma área híbrida, o que por um lado apresenta vantagens e por outro demonstra ambiguidades e conflitos.

Por fim, sugere-se a proposição de estudos que possam as subsidiar ações educacionais do docente da área e avançar no sentido de inovação de metodologias de ensino de esportes na Educação Física Escolar.

\section{AGRADECIMENTOS}

À Coordenação de Aperfeiçoamento de Pessoal de Nível Superior (CAPES).

Agradecemos também as pessoas envolvidas no Programa Residência Pedagógica, principalmente as professoras preceptoras, que promoveram contato com referenciais teóricos e vivências que embasaram a presente pesquisa.

\section{REFERÊNCIAS}

ARAUJO, L.; NEIRA, M. G. O currículo da Educação Física em ação: análise do processo de significação das práticas corporais por parte dos sujeitos. Iniciação: o - Revista de Iniciação Científica, Tecnológica e Artística, São Paulo, v. 4, p. 1-17, 2014.

BARROS, P. M.; DOS REIS, F. P. G. Uma proposta de sistematização dos esportes não convencionais para as aulas de Educação Física das séries iniciais do ensino fundamental: o caso do tênis. 2013. Lecturas: Educación Física y Deportes, Bueno Ayres, v. 18, n. 186, nov. 2013. Disponível em: https://www.efdeportes.com/efd186/propostados-esportes-ano-convencionais.htm. Acesso em: 30 nov. 2018.

BETTI, M. Educação física, esporte e cidadania. Revista Brasileira de Ciências do Esporte, Florianópolis, v. 20, n. 2- 3, abr./set. 1999.

BETTI, M. Educação Física escolar: Do idealismo a pesquisa-ação. Rev. bras. Educ. Fís. Esp., São Paulo, v. 19, n. 3, p. 183-97, jul./set. 2005.

BETTI, M.; GOMES-DA-SILVA, P. N. Corporeidade, jogo, linguagem: a educação física nos anos iniciais do ensino fundamental. São Paulo: Cortez, 2019.

BETTI, M.; KNIJNIK, J.; VENÂNCIO, L.; SANCHES NETO, L. In search of the autonomous and critical individual: a philosophical and pedagogical analysis of the physical education curriculum of São Paulo (Brazil), Physical Education and Sport Pedagogy, v. 20, n. 4, p. 427-441, 2015. Disponível em : https://www.tandfonline.com/doi/pdf/10.1080/1 7408989.2014.882891?casa token=PI9An806zJE AAAAA:xgwjq7VWkcXo8N4K3MjWGGla-7gMMMPWUD51RX-oHv924GG9LNW50G5SaIJdfK5scQRH9jtBJy. Acesso em: 30 nov. 2018. DOI:10.1080/17408989.2014.882891

BRACHT, V. Educação Física e aprendizagem social. Porto Alegre: Magister, 1992.

BRACHT, V. Educação Física \& Ciência: cenas de um casamento (in)feliz. 4. ed. Ijuí: Unijuí, 2014.

BRASIL. Coordenação de Aperfeiçoamento de Pessoal de Nível Superior (CAPES). Portaria GAB no 38, de 28 de fevereiro de 2018. Institui o Programa de Residência Pedagógica. Brasília, 2018. Disponível

em: $\quad$ http://www.capes.gov.br/educacaobasica/programa-residencia-pedagogica. Acesso em: 10 dez. 2020.

CANESTRARO, J. F.; ZULAI, L. C.; KOGUT, M.C. Principais dificuldades que $\mathrm{o}$ professor de Educação Física enfrenta no processo ensinoaprendizagem do ensino fundamental e sua 
influência no trabalho escolar. In: CONGRESSO NACIONAL DE EDUCAÇÃO - EDUCERE, 8., CONGRESSO IBERO-AMERICANO SOBRE VIOLÊNCIAS NAS ESCOLAS, 3., 2008, Curitiba. Anais..., Curitiba: Champagnat, 2008. p. 1232712336, 2008.

CESANA, J. et al. Educação física e corporeidade: Paralelos históricos, formação profissional e práticas corporais alternativas. São Paulo: CREF4/SP, 2018.

INTERNATIONAL OLYMPIC COMMITTEE. Tokyo Olimpic Games. Olympic Sports. Tokyo, 2018. Disponível em: https://tokyo2020.org/en/sports/. Acesso em: 03 set. 2020.

KUNZ, E. Educação Física Ensino e Mudanças. 3. ed. Ijuí: Unijuí, 2012.

KUNZ, E. Transformação didático pedagógica do esporte. 8. ed. ljuí: Unijuí, 2014.

LOPES, Y. M. S.; TAVARES, O.; SANTOS, W. O material de apoio curricular para a Educação Física do Estado de São Paulo segundo as tipologias dos conteúdos. Movimento, Porto Alegre, v. 23, n. 3, p. 813-826, set. 2017. Disponível em: https://www.seer.ufrgs.br/Movimento/article/vi ew/62988/43867. Acesso em: 14 mai. 2020. DOI: $\underline{10.22456 / 1982-8918.62988}$

MEDINA, J. P. S. A Educação Física cuida do corpo... e "mente". 10. ed. Campinas: Papirus, 1992.

MILANI, A. G.; DARIDO, S. C. Os conteúdos longitudinais no currículo de educação física do estado de São Paulo. Pensar a Prática, Goiânia, v. 19, n. 2, p. 448-461. Abr./jun. 2016. Disponível em:

https://www.revistas.ufg.br/fef/article/view/332 01. Acesso em: 10 dez. 2020. DOl: 10.5216/rpp.v19i2.33201

NEIRA, M. G. O currículo cultural da Educação Física: uma resposta aos dilemas da contemporaneidade. Revista Linhas, Florianópolis, v. 06, n. 31, p. 276-304, mai/ago, $2015 . \quad$ Disponível em: https://www.revistas.udesc.br/index.php/linhas/ article/view/1984723816312015276/pdf 73.

Acesso em 14 maio 2020. DOl:

\section{$\underline{10.5965 / 1984723816312015276}$}

NEIRA, M. G. Análises dos currículos estaduais de Educação Física: inconsistências e incoerências percebidas. Cadernos Cenpec, São Paulo, v. 5, n. 2, jun. 2016. Disponível em:

http://cadernos.cenpec.org.br/cadernos/index.p $\mathrm{hp} /$ cadernos/article/view/340/336. Acesso em: 14 mai. 2020.2 DOI: 10.18676/cadernoscenpec.v5i2.340

ORTIZ, H. M. O professor reflexivo: (re) construindo o "ser" professor. In: CONGRESSO DE EDUCAÇÃO DO MOVIMENTO HUMANIDADE NOVA, EDUCAÇÃO A FRATER-NIDADE: UM CAMINHO POSSÍVEL? 4., Vargem Grande Paulista. Anais... Vargem Grande Paulista: Movimento Humanidade Nova, 2003.

RUFINO, L. G. B.; BENITES, L. C.; SOUZA NETO, S. Os desafios para o desenvolvimento do trabalho docente na perspectiva de professores de Educação Física. Revista Corpoconsciência, Cuiabá, v. 21, n. 03, p. 55-65, set./dez. 2017.

SÃO PAULO (ESTADO). Secretaria da Educação. Currículo do Estado de São Paulo. Linguagens, Códigos e suas Tecnologias. Ensino Fundamental - ciclo Il e Ensino Médio. São Paulo, 2014.

SÃO PAULO (ESTADO). Secretaria da Educação. Coordenadoria de Informação, Monitoramento e Avaliação Educacional. Censo escolar estado de São Paulo informe 2014. São Paulo, 2015. Disponível em: https://www.educacao.sp.gov.br/censo-escolar/. Acesso em: 25 jun. 2018.

SANTIN, S. Esporte educacional: esporte na escola e esporte da escola. In: SIMPÓsIO NACIONAL DE EDUCAÇÃO FÍSICA, 26., 2007, Pelotas. Anais..., Pelotas: UFPEL, 2007. p. $254-$ 265, 2007.

SAVIANI, D. Pedagogia histórico-crítica: primeiras aproximações. 6. ed. Campinas, SP: Autores Associados, 1997.

SEDORKO, C. M., \& FINCK, S. C. M. Sentidos e significados do desporto no contexto da Educação Física escolar. Journal of Physical Education, v. 27, n. 1, p. 2745-2745, 2016. Disponível em: http://www.periodicos.uem.br/ojs/index.php/Re 
vEducFis/article/view/28572/17171. Acesso em: 10 dez. 2020. DOl:10.4025/iphyseduc.v27i1.2745

SMYTH, J. Teacher's work and politics of reflection. American Educational Research Journal, v. 29, n. 2, p. 267-300, 1992. Disponível em:

https://jamanetwork.com/journals/jama/articleabstract/394449. Acesso em: 10 dez. 2020. DOI:10.1001/jama.1992.03480020110047

SOARES, C. L., et al. Metodologia do Ensino da Educação Física. São Paulo: Cortez, 1992. (Coleção Magistério $2^{\circ}$ grau - série formação do professor).

SOUZA, J. A.; PAIXÃO, J. A. A prática do bom professor de Educação Física na perspectiva dos alunos do ensino médio. Rev. bras. Estud. pedagog., Brasília, v. 96, n. 243, p. 399-415, maio/ago. $2015 . \quad$ Disponível em: https://www.scielo.br/scielo.php?script=sci artte xt\&pid=S2176$66812015000200399 \& \operatorname{lng}=p t \&$ tlng=pt. $\quad$ Acesso em: 10 dez. 2020. DOI: $10.1590 /$ S2176$\underline{6681 / 333612962}$

TARDIF, M.; LESSARD, C. O trabalho docente: elementos para uma teoria da docência como profissão de interações humanas. Petrópolis, RJ: Vozes, 2005.

THOMAS J. R.; NELSON J.K. Métodos de Pesquisa em Atividade Física. 6. ed. Porto Alegre: Artmed; 2012. 